\title{
A new species of the tachyine genus Tasmanitachoides from the Kimberley Division, Western Australia (Coleoptera, Carabidae)
}

\author{
Martin Baehr \\ Zoologische Staatssammlung, Münchhausenstr. 21, D-81247 München, \\ Germany. E-mail: martin.baehr@zsm.mwn.de
}

\begin{abstract}
Tasmanitachoides mandibularis sp. nov. is described from the eastern margin of the Kimberley Division, north-western Western Australia. The new species is most similar to T. obliquiceps (Sloane) from eastern Australia, but is distinguished by its smaller size, shorter and wider elytra, less distinct elytral striation, longer and more conspicuous pilosity on the upper surface, and finely punctate pronotum. The new species is inserted in the most recent key to the genus Tasmanitachoides.
\end{abstract}

Keywords - taxonomy, new species, Kimberley Division, Western Australia, Tasmanitachoides

\section{INTRODUCTION}

The carabid fauna of Australia is highly diverse with representatives of 36 subfamilies, about 300 genera, and almost 2,600 species and subspecies (Moore et al. 1987; Baehr, unpublished checklist). The number of undescribed or even undetected species certainly is substantial and may amount to an additional 1,000 species. Since Moore's catalogue (Moore et al. 1987) about 700 species have been described, partly in the course of generic revisions using the ample unidentified material present in various Australian and foreign collections, but also from material collected recently in remote areas of northern and interior Australia. Further application of both methods, revisions of those large genera which were not worked for about 100 years, and systematic sampling in little collected parts of Australia, using specialized sampling methods (e.g. light collecting, fogging, sifting, pitfall traps, intercept traps), in future will allow a better knowledge of the number of existing species and their distribution.

During a collecting trip through northern parts of Western Australia and Northern Territory devoted to systematic light sampling at many water courses, a few specimens of a new species of genus Tasmanitachoides Erwin was collected at black light near sandy river beds. At the first glance the new species seemed very similar to the eastern Australian T. obliquiceps (Sloane), but differed from that species in some character states of size, body shape and surface structure, and therefore is herein described as a new species.

\section{MATERIALS AND METHODS}

The holotype of the new species is lodged in Western Australian Museum, Perth (WAM), paratypes are in the Australian National Insect Collection, Canberra (ANIC), and in the working collection of the author in Zoologische Staatssammlung, München (CBM).

The description follows the style used in my recent papers about Tasmanitachoides (Baehr 2008a, b). In view of the very small size of the specimens, drawing of the habitus was preferred to better show presence and distribution of the tactile setae, than would be possible when taking photographs.

Measurements were taken with an ocular micrometer, using a bifocal Leitz Stereo Microscope which has objectives with extremely high intensity and very high resolution. Body length has been measured from apex of labrum to apex of elytra. Body lengths, therefore, may slightly differ from those specified by other authors. Length of the pronotum was measured from the middle of apex to the most advanced part of base. Length of the elytra was measured from the most advanced part of humerus to the very apex.

For the examination of the fine though taxonomically important microstructure of the 
surface up to $160 \mathrm{x}$ magnification was used. For exact definition of the microsculpture two very bright Wild lamps were used that give natural light and can be focussed.

\section{SYSTEMATICS}

\section{Family Carabidae Latreille, 1802}

\section{Subfamily Trechinae Bonelli, 1810}

Tribe Trechodini Jeannel, 1926

\section{Genus Tasmanitachoides Erwin, 1972}

Tasmanitachoides Erwin, 1972: 2; Moore et al. 1987: 144; Baehr 1990: 868; Baehr 2001: 2; Baehr 2008a: 13; Baehr 2008b: 121.

\section{Type species}

Bembidion hobarti Blackburn, 1901, by original designation.

\section{Remarks}

This genus of small to very small, more or less elongate, Perileptus-like, mostly sand or gravel inhabiting ground beetles, was founded by Erwin (1972) who included those species that were placed by Darlington (1962) in his "hobarti-group" within the genus Tachys Dejean, 1821 sensu lato. Baehr (1990) revised the genus and included certain species not mentioned by Darlington nor Erwin, and described additional species. Three additional species from north-eastern Queensland and one from north-eastern New South Wales were described more recently (Baehr 2001, 2008a, b). At present, this genus contains 20 species which are distributed in eastern Australia (including Tasmania) and tropical northern Australia including the southern half of Cape York Peninsula and the Kimberley Division in northwestern Australia. A single species (T. arnhemensis Erwin), however, ranges far inland into the centre of Western Australia and also into Central Australia (see Baehr 1990: Figure 45).

Species of Tasmanitachoides combine some archaic bembidiine character states as enumerated by Erwin (1972) with characters that have similar states in the trechine complex. Erwin regarded these similarities as remnants of an archaic trechine-bembidiine stock, but analyses using molecular techniques (Maddison, pers. comm.) and the examination of the recently recorded larva of one species (Grebennikov 2008) indicate that Tasmanitachoides indeed belongs to the trechine rather than the bembidiine stock and should be included in the trechine tribe Trechodini.

The main body of the genus can be roughly divided into two groups which not only differ in colouration, but also in their preference for different habitat types. One group which includes the recently described species from Queensland and New South Wales (Baehr 2001, 2008a, b) (T. glabellus Baehr, T. balli Baehr, T. hackeri Baehr and T. hendrichi Baehr) prefer damp, usually montane, habitats at the banks of rivers and creeks in eastern Australia (Baehr 1990: Framenau et al. 2002), and usually are more or less dark coloured, whereas the other group consists of pale yellow or reddish species which mainly live in semiarid or even arid northern Australia and occur in sand or gravel of rivers, including intermittent water courses, provided that some pools in the river bed persist (T. arnhemensis Erwin, T. fitzroyi Darlington, T. katherinei Erwin and T. minor Baehr).

The eastern species T. obliquiceps, however, is unique in two character states of external morphology and is mainly distinguished by its trapezoid pronotum and the large, voluminous head which bears very elongate, decussate mandibles. It is light coloured, and in shape and structure closely resembles species of the subgenus Pyrrhotachys Sloane, 1896 of the trechine genus Perileptus Schaum, 1860. Unfortunately nothing is known so far about its ecological requirements.

The new species from the Kimberley region of northern Western Australia described in this paper exactly matches T. obliquiceps in all important group-defining character states.

\section{Tasmanitachoides mandibularis sp. nov.}

Figures 1-3

\section{Material examined}

\section{Holotype}

Australia: Western Australia: Ô, Little Panton River crossing, $56 \mathrm{~km} \mathrm{~N}$ of Halls Creek, Great Northern Highway, $17^{\circ} 52.53^{\prime} \mathrm{S}, 17^{\circ} 49.91^{\prime} \mathrm{E}$ (site Australia07, WA56), 339 m, 17-18 November 2007, M. Baehr (WAM Entomology no. 71228).

\section{Paratypes}

Australia: Western Australia: $1 \hat{0}, 1+$, collected with holotype ( + , ANIC; $\left.{ }^{2}, \mathrm{CBM}\right) ; 1$, Ord River crossing, $102 \mathrm{~km}$ NNE of Halls Creek, Great Northern Highway (site Australia07, WA84), 296 m, $17^{\circ} 28.74^{\prime} \mathrm{S}, 127^{\circ} 57.11^{\prime} \mathrm{E}, 26-27$ November 2007, M. Baehr (CBM).

\section{Diagnosis}

Tasmanitachoides mandibularis most closely resembles T. obliquiceps from eastern Australia, but is smaller $(<1.85 \mathrm{~mm}, T$. obliquiceps $>2 \mathrm{~mm})$, with shorter and wider elytra (ratio length/width $<1.68$, T. obliquiceps $>1.75$ ), has less distinct elytral striation, narrower, finely but distinctly punctate 
pronotum, and distinct, erect pilosity on the surface of pronotum and elytra.

\section{Description}

\section{Adult}

Measurements: length $1.72-1.84 \mathrm{~mm}$; width 0.59-0.62 mm. Ratios: width/length of pronotum 1.28-1.32; width widest diameter/base of pronotum 1.38-1.41; width pronotum/head 0.98-1.01; length/ width of elytra 1.63-1.68.

Colour: body including mouth parts, antennae, and legs uniformly, more or less pale, yellow.

Head (Figure 1): voluminous, about as wide as pronotum. Anterior margin of clypeus not impressed. Mandibles elongate, decussate, near apex suddenly incurved. Eyes small (in genus), moderately protruded, about as long as orbits, shortly and sparsely pilose. Orbits convex, gently sloping into neck. Clypeus bisetose on either side, labrum at apex rather deeply excised, six-setose. Penultimate palpomere of maxillary palpus globose, terminal palpomere narrow but elongate. Both palpi sparsely pilose. Antenna short, surpassing base of pronotum by about one antennomere,

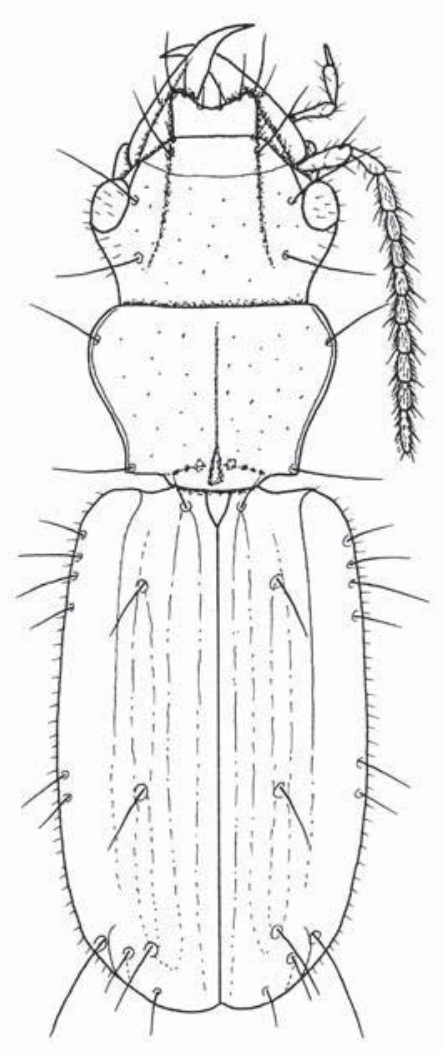

Figure 1 Tasmanitachoides mandibularis sp. nov., habitus (length: $1.8 \mathrm{~mm}$ ). antennomeres decreasing in length towards apex, apical antennomeres about as long as wide. Scapus sparsely setose, the following antennomeres more densely setose. Frontal furrows deep and long, running from anterior margin of clypeus, anteriorly almost parallel, posteriorly distinctly divergent, surpassing the eye and almost attaining the posterior supraorbital seta which is far removed from posterior margin of the eye. Surface very glossy, with very sparse, fine punctures, and with extremely short, erect pilosity; microreticulation absent. Also the lateral margin behind eyes with very short pilosity.

Pronotum (Figure 1): wide, much wider than long, markedly cordiform, widest very shortly behind apex, at the apical sixth, considerably narrowed to base. Lateral margins in anterior two thirds convex, then slightly sinuate to the rectangular, very acute basal angles. Apex straight, anterior angles not produced, base in middle much produced, laterally deeply excised. Apex and base not margined, lateral margin extremely narrow, no lateral channel developed. Dorsal surface moderately convex. Median line well impressed, not attaining apex, near base widened to a longitudinal furrow. Anterior transverse sulcus very shallow, transverse basal sulcus deeply impressed, laterally punctate, in middle interrupted by the deep furrow. Disk very glossy, without microreticulation, with sparse, fine, though well visible punctures and with sparse, fairly distinct, erect pilosity. Anterior marginal seta situated at widest diameter at apical sixth, posterior seta at basal angle.

Elytra (Figure 1): comparatively short and wide, posteriorly perceptibly widened, widest in apical third, surface moderately depressed. Humeri rounded, little projected. Inner five striae indicated, but liitle impressed, outer striae not recognizable. Striae 1, 2, and 5 originating at base, striae 3 and 4 basally shortened, jointly arising form position of anterior puncture. Stria 5 anteriorly conspicuously bent outwards to meet the humerus. All striae diminishing in apical third. Striae irregularly impressed, posteriorly consisting of irregular punctures. Recurrent stria very short. Their discal punctures and setae present, punctures fairly large, located near stria 3. Umbilical punctures and setae reduced to four behind humerus, two in middle, and one each outside and inside the deeply impressed submarginal sulcus that forms the apical part of stria 7, and a short seta situated at position of end of stria 3. Punctures rather foveiform. The complete margin of the elytra sparsely and very shortly pilose from behind humerus. Surface very glossy, without any traces of microreticulation, intervals with irregular uniseriate punctures and rather distinct, erect pilosity.

Posterior wings: fully developed. 
Lower surface: metepisternum elongate, ca. 2 x as long as wide at anterior margin. Prosternum and abdomen with moderately sparse pilosity. Abdominal sternum VII in male bisetose, in female quadrisetose.

Legs: protibia oblique at outer apical edge. Two basal tarsomeres of male protarsus asymmetrically widened and squamose.

Male genitalia (Figure 2): genital ring narrow and very elongate, narrowed to apex, almost symmetric. Aedeagus rather compact, lower surface very slightly convex, apex rather short (in genus), obtuse at tip. Orificium elongate, situated at the upper left side. Internal sac in middle with two twisted, sclerotized plates coiled into each other, both anteriorly ending in an elongate sclerotized rod. Both parameres large (in group), triangular, and with three elongate apical setae.

Female gonocoxites (Figure 3): both gonocoxites very slender and elongate. Gonocoxite 1 somewhat boomerang-shaped, without any setae at apical margin. Stylomere 2 almost straight, with a very elongate nematiform seta right on apex, and one short nematiform seta each at internal and external margins close to apex.

Variation: very little variation noted between the specimens.

\section{Etymology}

The species name refers to the elongate, decussate mandibles of this species.

\section{Distribution}

Tasmanitachoides mandibularis has been found on the eastern margin of the Kimberley Division, north of Halls Creek, northern Western Australia. It is so far known only from two localities. The specimens were collected with black light near the sandy river beds of Little Panton River and Ord River.

\section{Remarks}

As discussed earlier, T. mandibularis is most similar to T. obliquiceps which is known from eastern Australia, with which the new species forms a unique subgroup within the genus, mainly based on the morphology of the head with comparatively small eyes and very elongate mandibles, the trapezoid shape of the pronotum, and the remarkably depressed, pilose surface of the elytra.

The light colour, depressed body, small eyes, and elongate mandibles of the eastern Australian species T. obliquiceps suggest its occurrence in sand or gravel of rivers and creeks, but so far virtually nothing was known about its biology. Until recently, only the four specimens of the type series were available for study (Baehr 1990), although in the meantime I have seen several additional specimens from Shoalhaven River Gorge in south-eastern New South Wales, collected "in sand/mud", which not only enlarges the recorded range of this species considerably to the south, but also give a vague indication of its habitat requirements. Its apparent sister-species from north-western Australia, $T$.
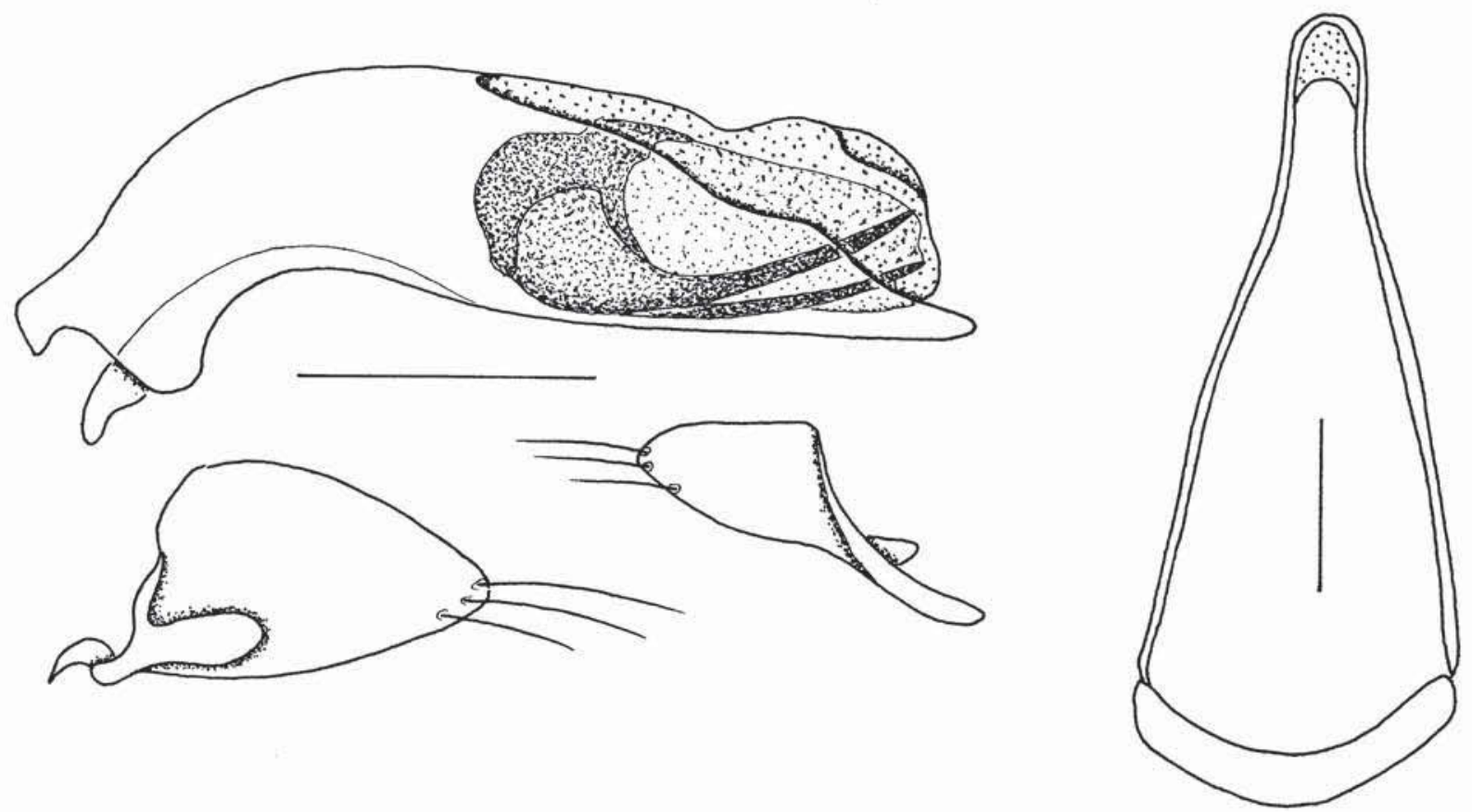

Figure 2 Tasmanitachoides mandibularis sp. nov.: Male aedeagus, left side, left and right parameres, genital ring. Scale lines $=0.1 \mathrm{~mm}$. 


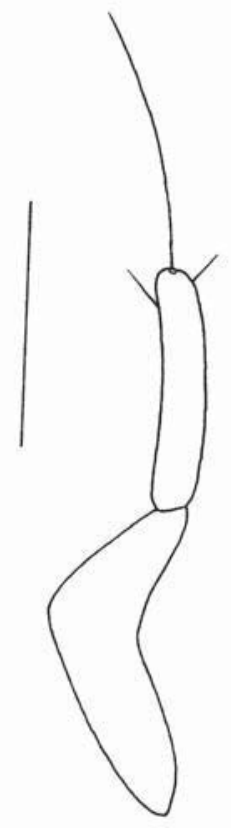

Figure 3 Tasmanitachoides mandibularis sp. nov.: Female gonocoxites. Scale lines $=0.1 \mathrm{~mm}$.

mandibularis, likewise was collected near the sandy beds of rivers, but the specimens were collected using black light, which sheds little information on its precise habitat requirements. Some collecting by hand on and in the sandy banks of Little Panton River did not reveal any additional specimens.

At first glance the occurrence of a close relative of the eastern species in the Kimberley Division seems surprising, but as the fauna of tropical northern Australia is increasingly better recorded, the amount of similar species, or at least, closely related species with comparable ecological requirements, in north-eastern and north-western Australia, respectively, is being considerably raised. In particular the Kimberley Division in extreme north-eastern Western Australia is home to many species that are quite similar to their eastern relatives in North Queensland, but usually they are apomorphic in certain respects and thus, most probably represent offspring of eastern species that have invaded this area but later were separated, and subsequently developed into separate but still closely related species. As Baehr (1992) suggested, such range extensions and dissections may have occurred within several carabid groups and, because most of the respective species are closely related, separation of the western species are considered fairly recent events that probably were caused by oscillations of climate and subsequent repeated expansion and retreat of vegetation zones during Glacial Period.
To facilitate identification of the new species in the most recent complete key to the genus Tasmanitachoides (Baehr 2008a: 16-18) follow on to caption 13, which is altered as follows:

13. Elytra parallel, depressed; eyes small, depressed, with well developed orbits, posterior supraorbital seta situated far behind eye (Figure 1); mandibles very elongate, decussate; pronotum trapezoid, widest shortly behind anterior angles; colour testaceous.....................13a

Elytra less parallel and less depressed; eyes larger, more protruded, orbits small; posterior supraorbital seta situated immediately at posterior border of eye; mandibles shorter, not decussate; pronotum laterally more convex, widest far behind anterior angles; colour reddishtestaceous to black. .14

13a. Larger species, body length $>2 \mathrm{~mm}$; pronotum wider, ratio width/length $>$ 1.35; elytra longer, ratio length/width > 1.75; pronotum impunctate; pilosity on pronotum and elytra barely visible even under high magnification (eastern New South Wales and eastern Queensland ........Tasmanitachoides obliquiceps (Sloane)

Smaller species, body length $<1.85 \mathrm{~mm}$; pronotum narrower, ratio width/length < 1.32; elytra shorter, ratio length/width < 1.68; pronotum finely punctate; pilosity on pronotum and elytra distinct, erect (north-western Western Australia)..... ......Tasmanitachoides mandibularis sp. nov.

\section{ACKNOWLEDGEMENTS}

I am indebted to the Deutsche Forschungsgemeinschaft (DFG) for supporting my travel by the grant Ba-856/10-1.

\section{REFERENCES}

Baehr, M. (1990). Revision of the Australian ground-beetle genus Tasmanitachoides Erwin (Insecta: Coleoptera: Carabidae: Bembidiinae), with special regard to the tropical species. Invertebrate Taxonomy 4: 867-894.

Baehr, M. (1992). An introduction to the biogeography of the Carabidae of montane refugia in northern Australia (Coleoptera: Carabidae) (pp. 67-78). In: G. R. Noonan, G. E. Ball, N. E. Stork (eds): The biogeography of Ground Beetles of Mountains and Islands. Intercept: Andover, UK.

Baehr, M. (2001). Tasmanitachoides Erwin glabellus n. sp. from North Queensland, Australia with a note on Tasmanitachoides lutus (Darlington) (Insecta, Coleoptera, Carabidae, Bembidiinae). Animal Biodiversity and Conservation 24: 1-7.

Baehr, M. (2008a). Two new species of the genus 
Tasmanitachoides Erwin from North Queensland, Australia (Insecta, Coleoptera, Carabidae, Bembidinae). Annals of the Carnegie Museum 77: 13-19.

Baehr, M. (2008b). A new species of the tachyine genus Tasmanitachoides Erwin from northern New South Wales, Australia (Coleoptera, Carabidae, Bembidiinae, Tachyini). Mitteilungen der Münchner Entomologischen Gesellschaft 98: 121-126.

Darlington, P.J., Jr. (1962). Australian Carabid beetles XI. Some Tachys. Psyche. Cambridge 69: 117-128.

Erwin, T.L. (1972). Two new genera of bembidiine Carabid beetles from Australia and South America with notes on their phylogenetic and zoogeographic significance (Coleoptera). Breviora of the Museum of Comparative Zoology 383:1-19.
Framenau, V.W., Manderbach, R. and Baehr, M. (2002). Riparian gravel banks of upland and lowland rivers in Victoria (South East Australia): arthropod community structure and life history patterns in a longitudinal gradient. Australian Journal of Zoology 50: 103-123.

Grebennikov, V.V. (2008). Tasmanitachoides belongs to Trechini (Coleoptera: Carabidae): discovery of the larva, its phylogenetic implications and revised key to Trechitae genera. Invertebrate Systematics 22: 479-488.

Moore, B.P., Weir, T.A. and Pyke, J.E. (1987). Rhysodidae and Carabidae. In: Zoological Catalogue of Australia 4: 17-320. Australian Government Publishing Service; Canberra, ACT.

Manuscript received 19 June 2008; accepted 3 December 2008. 